\title{
Study on A System of systems of Life Cycle Quality Monitoring for Land force Strategic Missile System
}

\author{
LI Ke, JIANG Huixia, FAN Shuyi, LI Yan \\ 4th department, SHIJIAZHUANG Mechanical Engineering College, Shijiazhuang, HEBEI,CHINA, \\ 050003 \\ Ken_like@126.com
}

Keywords: land force strategic missile; quality monitoring; system of systems; life cycle; architecture

\begin{abstract}
Quality monitoring is a critical way to ensure quality of missiles and is valid guarantee for capability of missiles. The paper studies the constructive problem of a system of systems of life cycle quality monitoring for land force strategic missile in terms of the characteristics of missile equipment. The paper firstly presents the basic procedures, methods and effectiveness of U.S. and RUSSIA armies' quality monitoring system of missile equipment, then indicates the problems of quality monitoring of land force strategic missile based on analysis on the current situation of quality monitoring of land force strategic missile. At last, an idea about architecture of a system of systems of life cycle quality monitoring for land force strategic missile, which is established with hierarchy and all nodes, is introduced to solve the mentioned problem.
\end{abstract}

\section{Introduction}

Missile is one of typical high-tech weapons, more and more various strategic missiles are deployed in land force, which are able to be classified into antitank missile, portable antiaircraft missile and mounted antiaircraft missile. Missile has not only complicated high-tech constitutions, but also has high cost of research and development, production; especially it has the characteristics of long-term storage, one-shot etc. in comparison with other conventional land force weapons. It is the quality of a missile that a missile could be used to implement its goal. So a system of systems of life cycle quality monitoring for land force strategic missile is very necessary $[1,2]$. There are several different phases, which are divided into research, producing, storage and usage etc., before and after a missile is deployed to land force, and every phase has its own distinctive demands to quality of a missile. For one missile deployed in one operational unit of land force, there are always a few quantity of the missiles stored for training and operations. The stored time of a missile is perhaps several years or several decades' years, so it is a normal phenomenon that the stored time of a missile is further longer than its launching time. In fact, the main part of time of a missile on service is in "waiting" state and ready to be fired at any time. Hence, life cycle quality monitoring of every missile on service, specifically during its stored time, is very important for guarantee of its reliability, which is key to judge whether a missile has combat capability. Aiming at the characteristics of land force strategic missile, they include that distributed abroad, many different stored area, many species and versions, the paper supposes an idea about a system of systems architecture of life cycle quality monitoring system of land force strategic missile, which is established with hierarchy and all nodes. So it could be a reference to establish a system of systems of life cycle quality monitoring, and then prepare to guarantee and enhance the quality of land force.

\section{Summary on quality monitoring of U.S. and Russia missile}

U.S. and Russia, pays attention to research and development of missile, meanwhile to give emphasis on quality monitoring of missile. U.S. would make Stockpile Reliability Program (SRP) before one missile is deployed. SRP is depicted as figure1. Reliability and safety etc. of stored missiles are validated in SRP by means of period function test, quality reliability modeling, simulating test and component test of disassembly missile, which could provide scientific evidences 
for quality estimation of missile so as to keep missile combat capability. SRP would chronically track and monitor missile, integrate various data to analyze storage reliability for confirming storeroom limitation of missile. SRP uses test vehicle to commence function test for small missiles; and uses static devices to do it for large missiles. By function test, a failure missile could be repaired and restored usable situation. Wooden round missiles are generally undergone destructive test instead of function test, that is to say, reliability estimation of the kind of missile is mainly achieved by component test and flying test to confirm their shelf life in SRP. It has been verified by experiments that SRP is a valid mechanism to extend shelf life of missile and cut maintenance cost [3].

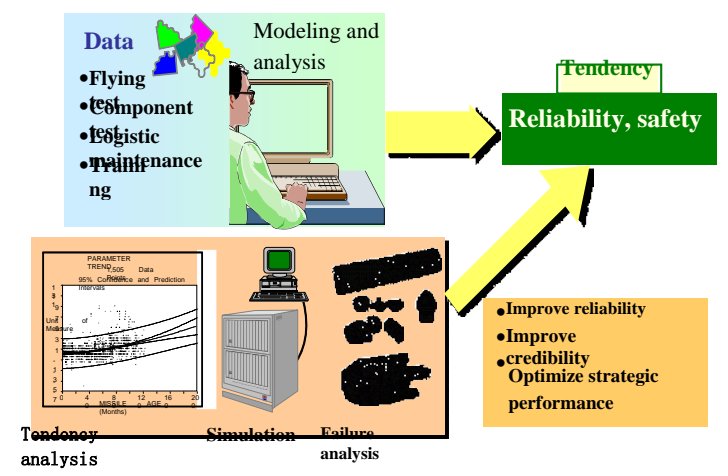

Fig.1. the foundational procedure of SRP

Among those SPR procedures, all of data required for making decision to extend missile shelf life are from function tests, laboratory tests and missile flying tests on storage missiles. For instance, the initial designed shelf life of TOW missile system is 5years; the initial designed shelf life of TOW missile system MLRS is 10 years. By means of comprehensive function tests, laboratory tests and missile flying tests, TOW missile system usable life is extended to 22 years, and MLRS missile system usable life is extended to 15 years. The benefits by performing SPR procedures include as follows: (1) hardware of missile reliability could be assessed; (2) the storage performances tendency of missile could be detected; (3) the failure components could be discarded from depositories. With background of diminishing of U.S.A. dollar, U.S.A. has developed many cheaper quality evaluating methods, for example, simulating test with diminishing destructive test, remote monitoring system etc. Under pressure of destructive test cost consumed for evaluating storage missile quality, U.S.A has more and more utilized history data or long-term performances testing data of missile, because these data could be analyzed to established time reliability models for storage missile and adjust the models with testing data for models effectiveness. So storage missile could be analyzed with established simulating model and scientific decisions could be made for storage missile quality control. According to U.S.A. 2012 projects of conventional missiles and nuclear weapons, research on time reliability models of storage missiles and nuclear weapons is still focus of U.S.A. From the projects published by DoD RIAC (Reliability Information Analysis Center) are cooperated with military and civilian research departments, the research critical points of RIAC includes reliability evaluating methods and development of evaluating tools, which indicates that U.S.A. pays more and more interest on quality evaluating methods and simulation. Missile reliability research is focus of U.S land force too. The department of U.S land force has carried out track and prediction for various types of missiles and their components, and a storage reliability database is established. The database has components storage reliability data, various reports of reliability experiments etc. With help of the database, not only could in-service missiles reliability be evaluated, but also new manufacture and designing methods of missile system could be provided. From twenty eighty time, Russia began accelerated storage life experiments and accelerated transport experiments. TORCH DESIGN INSTITUE has developed accelerated storage life experiment technology, which is composed of experiment principle, method, device and software. It has extensive applied in missile research, aerospace area etc., for example, C-300 antiaircraft missile. Through 6 months or shorter accelerated experiment time, 10 years of storage missile could be simulated and evaluated. That is to say, during the engineering research phase, weakness could be found through simulated storage experiments created by laboratory conditions, the actual effect or aged process of a product could be 
calculated and proper improvement could be adopted too. The qualified storage period of a product could eventually be gained. For verifying the job capability of a missile in various environments, the technology could simulate and revive several environment conditions of deploying area and typical laboratory, the technology is more efficient than conventional storage experiments without multiple environment conditions. So a missile conducted by accelerated storage life experiment technology could not be detected and repaired during its long-time storage process.

\section{Current situation of China missile quality monitoring}

China also pays more attention on research of missile quality monitoring too. The research began from the 1950s and gets some results on ammunition and missile storage reliability. For example, the research of ammunition long-time storage reliability from the 1958 has got the law of ammunition storage quality change and other results after one hundred thousand ammunition storage experiment. From the 1960s later, China first generational tactic and strategic missiles step by step began field storage experiments. The research has accumulated many experiences. Second artillery has made tactic missile relevant military standard, which has specified tactic missile reliability requirement and process control and requirement of reliability, the standard erects basement for missile initial quality. From 1981, a research on ballooning missile storage reliability has been executed and its reliability analysis method has been got. In 1995, a serial navy in-service missile quality monitoring standards have been made, in which the general requirements about composed tasks, quality prediction, quality analysis, quality information management and quality decision are designed, and the main content and jobs of quality monitoring is indicated, the quality hierarchy and evaluation method is given. The serial standards are adaptive to navy in-service missile, and it is a doctrine to organizations including navy forces, stores, maintenance forces and commands, which are responsible to commence quality monitoring. From 1986, an extended shelf life experiment for an antitank missile was begun and the strategic storage reliability research was studied too, which is the foundation to formulate standards of various equipment reliability requirements. At present, land force forces perform quality monitoring and get missile quality information by period or unscheduled detection method; the velocity of missile quality degradation is controlled and postponed by environment temperature and humidity controlling. But because the characteristics of land force operations, which are more flexible and larger battle area compared with navy, air force, second artillery, so land force missiles couldn't be stored as the way of concentrated or base management and storage of navy, air force, second artillery. The storage area of land force missile is distributed in larger area and the environment stresses has more differences, which causes land force missile quality information not only to be difficultly integrated, but also to be endured different 'pollution'. Besides that, the limited storage missile amount results in many electric technological performance detection than little sampling detection of missile overall performance, so the overall decision for missile quality is confined. Hence, a missile quality monitoring database which has each site and multiple hierarchies should be used in land force missile quality monitoring. The missile life cycle quality monitoring is commenced by sampling data of the same quality or the same type, reliability data and reliability data of missile components.

\section{Design on a system of systems of life cycle quality of land force strategic missile}

The content of quality monitoring includes quality detection, quality analysis and decision control. So an architecture constituted by each site and multiple hierarchies could be used for a system of systems of life cycle quality of land force strategic missile [4, 5], in which different layer has own job and responsibility, but quality information could be shared. So it is not only equipment managing departments to implement quality monitoring, but also multiple layer, multiple classes, multiple functions departments, for example, various different stores, maintenance departments etc. Besides collecting, classifying and transmitting each layer quality information, these departments due to integrate, track and analyze the information for relevant decision supporting. Establishing the hierarchical system of systems of life cycle quality of land force strategic missile to know missile 
storage amount, quality situation, analyzing quality changing law and the key factors of effecting quality, equipment management and technical handling jobs are scientifically commenced, the key problem of all above goals is to realize missile quality closed loop control, which is the core to transfer missile quality monitoring from the type of performance to the type of whole life span effectiveness. A system of systems of life cycle quality of land force strategic missile is constituted by headquarters layer, Theatre layer, division/brigade layer, battalion/company layer. Each layer is constituted by missile business department and relevant units. The basic quality information cards and quality monitors are installed in missile repairing factories, missile repairing centers and missile deployed forces. The architecture of a system of systems of life cycle quality of land force strategic missile is shown as figure 2 .

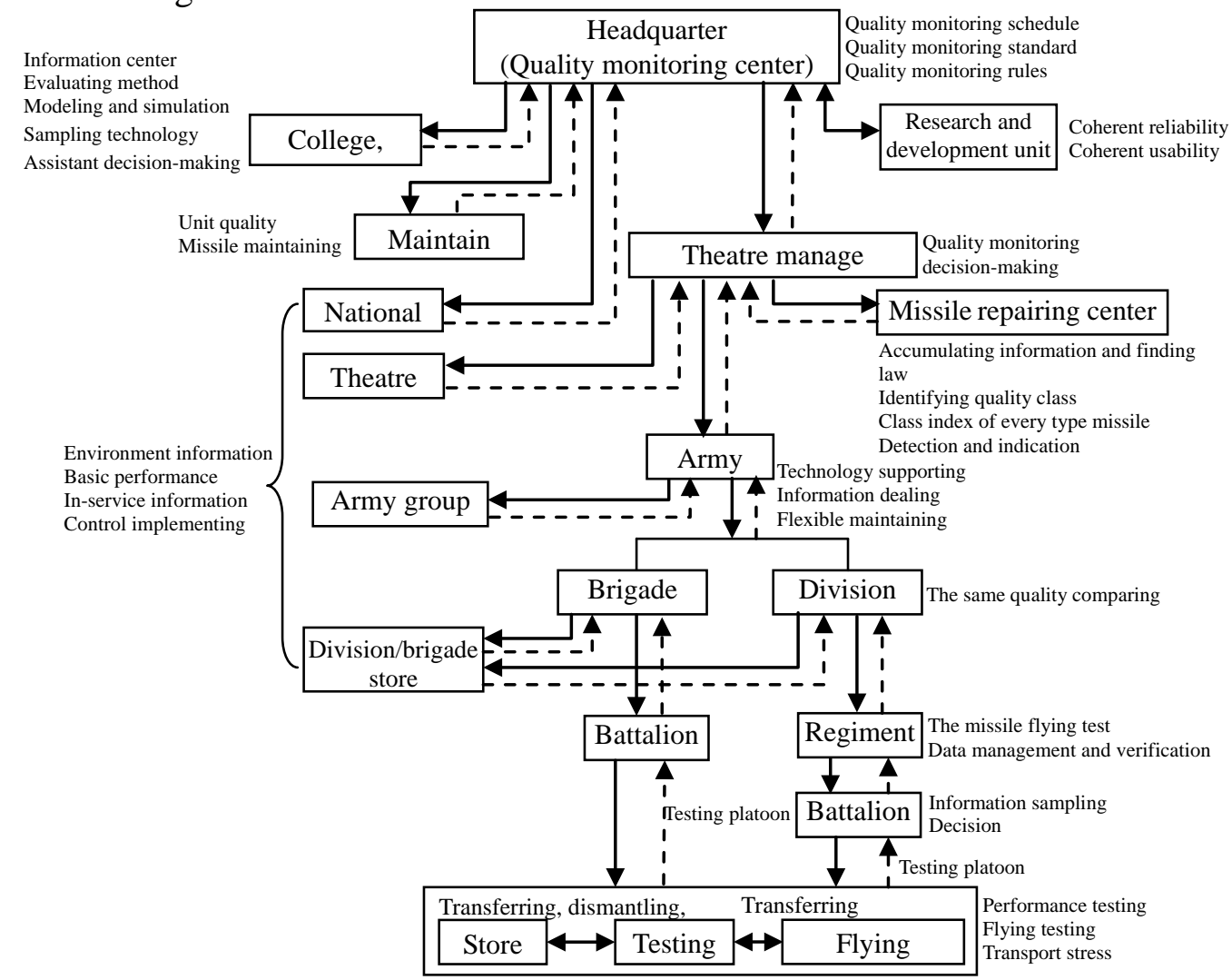

Fig.2. the architecture of a system of systems of life cycle quality of land force strategic missile

Different quality monitoring institutes has different responsibility; missile information is transmitted and shared among every layer to implement missile reliability closed loop control for storage missile whole life span from missile service to life end. Different layer information sampling terminal has different sampling device. Now that unit testing method and testing indexes of storage missiles have been decided in producing phase, the acquiring and way for storage environment information, transmitting environment information, usage environment information etc. is a focused problem for missile deployed forces information sampling terminals.

Missile quality information is included equipment coherent information, equipment basic information, performance detection and maintenance information, environment detection information, decision control information etc. The mentioned information should be collected at the time when missile is deployed and information of every missile should be collected too. Some coherent information, for example designed reliability, maintainability etc., has confirmed as missile equipment was designed. Basic information, for example missile number which is an only information code is used to identify the missile, should be confirmed as a missile is deployed. Performance detection and maintenance information is collected by usage units, stores and relevant units as missiles are transported, used, maintained, tested. Environment detection information is collected by usage units, stores and relevant units as missiles are transported and stored. Information center firstly implements comprehensive information handling according to missile storage quality information, flying experiment information and missile components quality 
information of various types and area, secondly reliability model is analyzed, in the end quality evaluating conclusion and improving measures are given too. Then the quality monitoring manage center commences missile quality control according to study report from information center.

\section{Conclusions}

Quality monitoring is a main method to confirm missile quality. At present, land force has pay more attention to missile quality detection, but it is still lack that the scientific method and a system of systems about manage and usage of missile quality information. Quality information has only output without re-feedback and re-control. Aiming to the land force missile characteristics of distributed area, multiple types, the paper establishes an architecture of a system of systems of life cycle quality monitoring for land force strategic missile, which is established with hierarchy and all nodes. The architecture could implement information share among missile quality layers and improve the control level of missile quality.

\section{References}

[1] Deng Xiang, ZHANG Bin, WEI Han. The Problems and Resolving on New Ammunition Quality Monitoring and Information, Ordnance Sergeancy [J], 2014 （1） : 32-33.

[2] NIE Lin, PAN Luwei, REN Fengyun. Analysis on Air to ground missile Quality, Quality and Reliability, 2011,6:25-26.

[3] PAN Wen-geng, WANG Xiao-ming, TAO Min, LI Wen-bin. The Failure Mechainism Analysis of Long-stored Ammunition, Journal of Projectiles, Rockets, Missiles and Guidance, 2007, $1(27): 122-125$.

[4] WANG LI. A Refurbishment Quality Management System Based on PDM/MES [D]. HUAZHONG UNIVERSITY OF SCIENCE AND TECHNOLOGY, 2013.

[5] JIN Guang. COMPLEX SYSTEM RELIABILITY MODELING AND ANALYSIS [ M], BEIJING: NATIONAL DEFENCE INDUSTRY PRESS, 2015. 